\title{
A Segregação Sócio-espacial como tema Gerador para Escolas de Periferias: Uma Experiência em Maricá ${ }^{1}$
}

\author{
Diego Jasmin Marino²
}

\section{Resumo}

Esta monografia tem por finalidade discutir a escolha de conteúdos que contemplem a realidade experimentada pelos alunos, apresentando uma experiência realizada em uma escola pública de periferia no município de Maricá - RJ. O ensino de geografia tem seguido o mesmo caminho que outras disciplinas escolares trilham, o de apresentar um currículo que valorize a memorização sem problematizar a realidade, desvalorizando assim a prática do aluno. Trabalhou-se nessa monografia, portanto, com a metodologia dos temas geradores, que busca no universo temático do sujeito a problematização da realidade. No colégio Estadual Euclydes Paulo da Silva que está localizado no bairro de São José de Imbassaí, região que apresenta sérios problemas, devido ao descaso das autoridades, chegou-se ao consenso com os alunos acerca do tema-gerador segregação sócio-espacial, como um tema muito presente em seu cotidiano.

Palavras-chaves: ensino de geografia; segregação sócio-espacial; tema gerador.

\section{Abstract}

This monograph aims to discuss the choice of content that address the reality experienced by the students, presenting an experience in a school in the outskirts of the city of Maricá - RJ. The teaching of geography has followed the same path as other school subjects tread, to present a curriculum that values the memorization without question the reality, thus devaluing the practice of the student. We will work in this article, therefore, the methodology of generating themes, looking at the thematic universe of the subject to questioning of reality. State College Euclydes Paulo da Silva who is located in São José de Imbassaí region, which presents serious problems due to the negligence of the authorities, we reached a consensus with the students about the socio - spatial segregation as a theme present in much their daily lives.

Key-words: teaching of geography; socio-spatial segregation; and theme . 


\section{Introdução}

A escola sempre foi motivo de discussão entre estudiosos que a enxergam como uma instituição importante de nossa sociedade. O processo de ensinoaprendizagem tem o papel de trabalhar com os alunos elementos da sua cultura. São inúmeros os questionamentos acerca desse processo, desde a maneira como ele ocorre, até a escolha dos conteúdos lecionados.

A geografia merece atenção especial pela sua evolução epistemológica. A disciplina passou por diversas mudanças no século $X X$, desde sua inclusão no currículo da escola brasileira. O ensino de geografia descritivo e que prioriza a memorização tem suas bases no próprio pensamento geográfico. Segundo Moreira (2006) o inicio da geografia como ciência prioriza os trabalhos de descrição da região, aonde os vários campos da ciência eram descritos separadamente. Segundo o autor esse é o embrião da geografia que prioriza esse modelo de aprendizagem.

Reforçada pela idéia de Lacoste (2008), segundo o qual os conteúdos lecionados na escola não são trabalhados visando o desenvolvimento do conhecimento pertinente a realidade em que o aluno está inserido. $O$ autor chega a dividir a geografia dos Estados maiores da geografia escolar, caracterizada como uma visão apenas parcial da realidade.

O presente trabalho promove um debate sobre a forma como esses conteúdos são escolhidos, relacionando isso à falta de interesse dos alunos pela escola. $\mathrm{Na}$ realidade este debate questiona as relações de poder que determinam a escolha de alguns conteúdos em detrimento de outros, promovida por um grupo restrito.

Observa-se que o currículo escolar, muita das vezes, não respeita a realidade dos alunos, sendo repassado para eles através do método de memorização, ou seja, sem problematizar esses assuntos, negligenciando ainda a relação desses com o cotidiano vivenciado por esses sujeitos. Esse modelo é responsável pela falta de sentido que os alunos tanto reclamam em seu dia-a-dia escolar. São cada vez mais presentes perguntas como: por que devo aprender isso? Esse modelo, inadequado ao desenvolvimento da prática de ensino, reafirma - status quo que caracteriza essa sociedade, uma vez que esses alunos não são convidados a discutir assuntos que estão relacionados com sua realidade.

Com base no trabalho de Freire $(1981,1983$, 1987), que propôs a investigação da realidade do aluno através da metodologia dos temas geradores, a presente pesquisa apresenta

uma experiência pedagógica, vivenciada com alunos do segundo ano do ensino médio, de uma escola pública localizada na periferia do município de Maricá, na região metropolitana do Rio de Janeiro. Propôs-se o desenvolvimento de conteúdos retirados do próprio universo temático do aluno, contextualizando-os no processo de segregação sócio-espacial.

Todo tema gerador deve ser escolhido através da participação dos alunos, através das experiências vivenciadas no cotidiano do bairro onde moram. Esse tema, 
portanto, foi escolhido através de um amplo debate com a comunidade local que reclamou muito da ausência do poder público na região, que não oferece serviços básicos à população.

Os alunos foram convidados a debater um assunto escolhido por eles, dentro da sua própria realidade; ou seja, a discussão parte de um problema compartilhado por todos os alunos que puderam expor sua opinião e propor soluções que superem a situação que vivem.

No Brasil, segundo Villaça (2001), o processo de urbanização foi marcado por uma intensa concentração de investimentos em algumas regiões. Esse processo foi responsável, pela marginalização de alguns lugares, onde se concentra a camada mais pobre da cidade. Essas regiões são desprovidas pelas ações do Estado. A segregação sócio-espacial é uma realidade vivenciada pelas pessoas que residem nas periferias das grandes cidades. A produção das cidades é feita por alguns agentes, dentre eles estão os alunos, que sem ter o conhecimento, participam dessa produção.

Sem desprezar o conceito científico, mas utilizando a metodologia dos temas geradores o objetivo é trabalhar a realidade do aluno em sala de aula, refletindo sobre a situação que ele compartilha com seus colegas de turma no cotidiano do bairro em que vive.

O presente trabalho começa com a discussão sobre a importância de uma proposta de ensino de geografia que coloque o aluno como sujeito de sua educação. Na segunda parte, a metodologia dos temas geradores é exposta como uma forma de apresentar ao aluno a sua realidade como conteúdo e, conseqüentemente, a sua importância dentro desse processo. Sendo finalizado com a experiência vivenciada em uma escola pública do município de Maricá.

\section{Ensino de Geografia: Por uma Educação Problematizadora}

Durante muitos anos se entendia a educação como a passagem de conhecimento das gerações mais antigas para as mais novas. A metodologia da prática educativa nos dias de hoje não acompanhou a necessidade dos alunos nos dias atuais. A busca por uma educação que traga a compreensão da realidade, através da conscientização do aluno é fundamental para a produção de uma sociedade mais justa. Uma educação que problematize essa situação, trazendo ao aluno uma reflexão sobre o processo se torna fundamental.

A escola é um campo cheio de contradições. Ela pode ser considerada um espelho do que acontece na sociedade. Uma dessas contradições está presente logo no início do processo de ensino-aprendizagem, na escolha dos conteúdos, quando o professor, em ação arbitrária apresenta o que vai lecionar enquanto o aluno chega à escola sem saber o que vai aprender. Os conteúdos são impostos pelos professores, sem muita das vezes buscar qualquer articulação com a realidade 
dos alunos com os quais trabalhará durante todo o ano letivo.

Essa prática pedagógica, sem a participação do aluno, demonstra um pouco do que significa a escola para a maioria das pessoas nos dias de hoje: o aluno não é um agente ativo de sua educação e não sabe, ao certo, quais os principais objetivos de estar na escola; o que resulta em todo o seu abatimento e falta de interesse por ela. Isso vai contra ao real objetivo de ensinar geografia, que tem como principal finalidade ajudar o aluno a compreender o mundo em que vive para nele atuar, ocupando seu lugar na vida democrática, como propõe Castellar (2009). Os problemas citados acima explicam alguns dos fracassos vivenciados pelos professores que lecionam geografia.

A necessidade de ensinar os conteúdos a partir da realidade experimentada pelo aluno cada vez mais se faz presente nos debates sobre o ensino de geografia. Na realidade, essa preocupação já figura há algum tempo no cenário nacional. Desde a criação do manual de estruturação do currículo estadual, criado por Darcy Ribeiro em São Paulo no ano de 1962, observa-se a preocupação do autor com a busca por trabalhar com a realidade do aluno.

Durante muitos anos as ações contrárias às propostas de Darcy Ribeiro foram maioria na educação nacional; currículos sendo elaborados sem a participação dos alunos e também dos professores das escolas, conteúdos sendo trabalhados pelos professores seguindo o método da memorização, tendo o aluno como um depósito de informações. Essa "didática de memorização", na realidade não permite que haja aprendizagem com significado sócio- cultural por parte do aluno, uma vez que, esse processo requer algo muito maior do que a simples memorização de algumas informações para colocar em uma possível prova.

É necessário compreender que a geografia tem uma abordagem filosófica voltada para a realidade social. Ao fugir dela, cria-se muito mais do que um simples erro metodológico, pois se perde sim o foco dos objetivos da disciplina. Trabalhar conceitos e conteúdos mecanicamente, visando à memorização, foge completamente aos objetivos da geografia na escola. Essa visão do ensino de geografia como uma coleção de conteúdos passados adiante em sala de aula, distancia os alunos de sua realidade e os professores dos alunos, fazendo com que os mesmos percam o sentido do que estão estudando e não aprendam a atuar perante situações que se apresentam em seu cotidiano.

Castellar (2009, p. 9) deixa isso claro ao mencionar que "espera que o aluno estude a partir de situações do cotidiano e relacione o conhecimento aprendido para analisar a realidade, atuando nela de maneira crítica". Portanto, é necessário que o ensino de geografia rompa, através da conscientização das massas, essas perspectivas da educação tradicional que visa à manutenção do status quo.

Como já foi amplamente discutido (Freire: 1981; Moreira: 2006; Straforini: 2008), não adianta apenas quebrar com a visão que busca a perpetuação dessa ordem, a metodologia de ensino também deve romper com essa opressão existente na escola. Isso fica claro com as severas críticas feitas por Straforini (2008) ao movimento da geografia marxista que chega à escola no fim dos anos 
90. Esse movimento demonstrou que há a necessidade em rever a metodologia de ensino, ou seja, não é somente o que é ensinado, mas precisamente como é lecionado. Esse movimento foi muito importante, pois inaugurou um momento na escola onde os professores trabalhavam os conteúdos sem a imparcialidade que supostamente existia. Eles discutiam os conteúdos com os alunos demonstrando claramente a sua visão política.

O grande problema desse modelo é que a sua metodologia de ensino é tão desinteressante quanto à dos professores anteriores ao movimento, uma vez que, o aluno continua a não ter uma participação efetiva em seu processo educativo, ele não constrói o conhecimento com o professor, continua recebendo-o pronto, sem formular sua própria opinião e por isso segue muitas das vezes sem conseguir dar sentido a escola.

É necessário também que o aluno deixe de assistir apenas a aula e passe a fazer parte dela, a ajudar a criar um curso que sirva para a conscientização dele e de sua comunidade para que ela deixe de ser apenas manipulada por aqueles que detém o real conhecimento do mundo. Uma educação que seja construída para os oprimidos e pelos oprimidos, o que vai de encontro à prática institucional da escola nos dias de hoje como afirma Straforini:

O que temos na educação de hoje é o impedimento de ações horizontalizadas, ou seja, ações pensadas e praticadas pelos professores e alunos dessa comunidade escolar. Temos, dessa forma, apenas ações verticalizadas, isto é, engendradas por burocratas que não conhecem a realidade da escola e muito menos tem vontade de transformá-la. (STRAFORINI, 2007 p.54)

É necessário que haja uma participação desses alunos nesse processo educativo, a fim de que tenham a compreensão do espaço que ajudam a produzir com suas práticas, qual a posição em que nele ocupam para assim atuar de acordo com os seus interesses.

A busca por uma nova metodologia de ensino vem sendo motivo de diversos debates nos encontros e simpósios de ensino. Um ponto importante e de confluência de ideias é a valorização do mundo experimentado pelo aluno. Hoje se verifica a importância de uma geografia que analise a realidade social da criança, permitindo a compreensão do espaço não como algo estático que serve para ser descrito.

Com o advento da globalização e com o choque entre as mais diversas culturas, criou- se uma oportunidade única de se trabalhar a relação local/global. Como não utilizar o desemprego vivenciado pelo aluno em sua família, amigos e conhecidos, relacionando com a reestruturação produtiva no século XX? Observase com a globalização uma facilidade cada vez maior em realizar esses tipos de 
trabalhos (global/local) onde o aluno vislumbre a sua participação no cenário mundial, descobrindo a existência e produção do espaço através de suas práticas.

São inúmeras as contribuições dos autores que reforçam a importância do papel da geografia na formação de um individuo que reconheça o seu papel e saiba resolver os diversos problemas que a sua realidade lhe apresenta.

Em sua obra, Cavalcanti (2005) advoga a favor da prática docente que trabalhe com uma escolha de conteúdos onde o sujeito seja o centro dessa escolha, ou seja, a criação de um plano de curso onde o educando participe da elaboração do mesmo. A partir daí ele se torna o centro de seu próprio processo educativo. Com isso entende-se a sua metodologia, na qual a aplicabilidade dos conteúdos científicos na escola deva partir dos conhecimentos cotidianos do aluno, reforçando a educação como uma prática de integração do aluno ao mundo através da conscientização. Observamos isso no trecho seguir:

Há um certo consenso entre os estudiosos da prática de ensino de que esse papel (da geografia) é o de prover bases e meios de desenvolvimento e ampliação da capacidade dos alunos de apreensão da realidade sob o ponto de vista da espacialidade, ou seja, de compreensão do seu papel na transformação do espaço. (CAVALCANTI: 2005, p.31)

O movimento da geografia crítica não foi o bastante para trabalhar o cotidiano do aluno, pois houve uma preocupação com o que ensinar, porém a metodologia da aprendizagem não foi tão discutida. De fato a geografia marxista teve uma importância fundamental para o ensino de geografia, uma vez que trouxe à escola a ideia de "luta de classes", o professor deve se engajar nos objetivos da classe trabalhadora. Muitos trabalhos valorizam esses conteúdos lecionados de maneira crítica. A obra de Lacoste (1987) foi pioneira nesse sentido, ao denunciar a diferença entre a "geografia dos estados maiores e a geografia dos professores" tendo a segunda o papel de esconder os reais fins políticos dessa disciplina.

O método de ensino nessa corrente, no entanto, deixou de ser discutido e por isso essa maneira de repassar uma série de conteúdos com uma visão política foi tão opressora quanto á geografia tradicional, uma vez que não fez da classe trabalhadora sujeito ativo de seu processo de ensino/aprendizagem.

Segundo Santos (1995) a geografia escolar se tornou ultrapassada por ter na base de sua estrutura algumas marcas da geografia tradicional. A formalidade ainda é um ponto forte da escola, não deixando as portas abertas para as necessidades apresentadas pelo alunado. É necessário que assim como a escola, a geografia se preocupe menos com as formalidades dos burocratas e o professor e a comunidade escolar tenham o maior controle sobre aquilo que irão estudar.

Como se observou, os autores citados convergem em alguns pontos importantes. O mais significativo deles é a importância de trabalhar os conteúdos 
através do mundo vivenciado pelo aluno uma vez que a partir dele promove-se uma conscientização perante os problemas enfrentados pelo sujeito em seu cotidiano.

Diante disso, propõe-se a busca de conteúdos que façam o aluno conhecer o seu mundo para ser capaz de romper com suas "situações limites". Sair dessa formalidade citada por Santos (2005) se faz fundamental para que a geografia tenha algum significado na vida desse aluno.

\section{A Construção de Conhecimentos a partir dos Temas Geradores}

Como se discutiu anteriormente, alguns movimentos surgiram na educação para superar essa escola tradicional; alguns, porém não ultrapassaram a discussão acerca da escolha dos conteúdos trabalhados, deixando o método de ensino num plano secundário. Alguns autores, entretanto, foram além dessas limitações, buscando renovação completa e uma prática libertadora de educação; dentre os quais destacou-se Paulo Freire.

A metodologia existente na escola atual, baseada na memorização de conteúdos externos a realidade do aluno, demonstra uma fragilidade perante a necessidade dos alunos. O conhecimento ganha relevância na vida do aluno, quando o mesmo serve para a aplicação em determinadas situações. Os temas geradores criados por Freire têm como proposta a construção de conhecimentos através da problematização da realidade do aluno, para que esse seja sujeito de sua educação e expresse na prática as teorias construídas em sala.

A ideia de educação desse autor supera a discussão sobre o que ensinar. Em sua proposta de ensino, fica evidente uma preocupação com o método e principalmente com os objetivos que são bem claros: a libertação da classe trabalhadora a partir da conscientização da mesma, partindo de sua própria realidade e chegando a objetos mais abstratos.

Para isso, critica o modelo de educação que existe na escola tradicional, onde segundo o próprio autor, é criada uma dicotomia entre o homem e o meio (Freire, 1981), como se o primeiro não fizesse parte do segundo e o processo de aprendizagem fosse o depósito de informações desse estranho mundo. Homens simplesmente no mundo e não com o mundo e com os outros. Homens expectadores e não criadores. Estes concebem sua aprendizagem sem compreender a importância de suas práticas sociais.

É a partir desses argumentos que o autor expõe as pesadas críticas a esse modelo de educação que, segundo o mesmo, é opressor e alienante. Para Freire esse método só serve para "encher" o aluno de falsos saberes (uma vez que conhecimento para o autor é diferente de informação), que dissociados da realidade não trabalham com a reflexão do aluno.

Esse método bancário (Freire, 1981) é caracterizado pela passividade dos educandos frente ao seu processo de ensino-aprendizagem, apenas servindo para 
adequar (oprimir) os alunos ao mundo desses opressores, que tem como objetivo recriminar seu pensar autêntico, como coloca o autor:

Esta é uma concepção que, implicando uma prática, somente pode interessar aos próprios opressores, que estarão tão mais em paz, quanto mais adequados estejam os homens ao mundo. $\mathrm{E}$ tão mais preocupados, quanto mais questionadores do mundo estejam os homens. A educação bancária serve a essa prática de alienação e opressão. (FREIRE: 1987, p.73)

A proposta do autor visa à libertação da classe trabalhadora, portanto é de uma educação problematizadora, onde os sujeitos só ganham autenticidade através da própria autenticidade de pensar dos educandos e tudo isso mediado por uma realidade.

Essa, portanto, não pode ser desprezada pelo professor comprometido com a conscientização desses alunos, que tem como obrigação inicial conhecer a realidade do aluno, o auxiliar na construção do conhecimento e em sua futura ação sobre o mundo. Por isto, essa educação tem dois pilares que a sustenta: a problematização, uma vez que, problematizar é trabalhar a realidade desses indivíduos numa perspectiva de conscientização para a ação sobre essa realidade. E a dialógica, porque só através do diálogo os homens se conhecem e se educam: não posso reconhecer a realidade dos alunos sem discutir a mesma com eles. Nessa proposta de educação deixa de existir, portanto, a divisão professoraluno, pois os dois aprendem e ensinam dialeticamente, sendo necessário o professor abrir mão dessa "autoridade".

Seguindo esse modelo, os temas geradores se fazem fundamentais para uma educação conscientizadora. Esses temas - que fazem parte da proposta Freiriana -, são construídos a partir do conteúdo envolvido nas "situações problemas" vivenciadas pelos alunos diariamente, servindo à sua conscientização e ao conhecimento do mundo em que vivem. Esses temas são extraídos das contradições vivenciadas pelos indivíduos, de sua situação existencial concreta e presente, como problema que, por sua vez, o desafie e, assim, lhe exige resposta não só no nível intelectual, mas no nível da ação.

A escolha por trabalhar com temas geradores exige abrir mão do monopólio na tomada de decisões relativas às escolhas dos conteúdos trabalhados em sala de aula. Essa metodologia supõe a ação do aluno, a participação dele que caracteriza o início da libertação da opressão da educação bancária. O papel do professor não é falar a esses indivíduos sobre nossa visão de mundo, nem impor a eles nossa opinião, mas construir e reconhecer o posicionamento deles através do diálogo que se faz necessário desde o primeiro contato. 
Para trabalhar com a visão de mundo do aluno e discutir temas que estejam no cotidiano do mesmo é fundamental que o professor conheça essa realidade, a reconhecendo não apenas através de sua visão do mundo, mas sim através dos indivíduos.

Dessa forma a busca pelos temas geradores só pode ser feita no diálogo com os alunos, a fim de compreender as situações problemas para a discussão e o início do encontro deles com o próprio mundo. É, portanto, na realidade problematizadora, na consciência que dela se tenha, educadores e povo, que se propõe buscar o conteúdo programático da educação, como propõe Freire:

Daí que conscientizadora também, proporcione, ao mesmo tempo, a apreensão dos "temas geradores"e a tomada de consciência dos indivíduos em torno deles mesmos. Esta é a razão pela qual não se trata de ter nos homens o objeto de estudo, mas eles investigando os problemas juntos de seu educador. (FREIRE: 1987, p.101)

O tema gerador, portanto, não é uma criação arbitrária que precisa de provas para comprová-lo, a investigação não é feita para isso, mas sim para saber se o tema está inserido no universo temático daqueles indivíduos.

Os temas têm como principal objetivo a conscientização através dos problemas vivenciados no próprio cotidiano dos indivíduos. Ao reconhecer os temas geradores como ponto de partida (e de chegada), não se deve esquecer que ele serve apenas como o início de um universo temático que precisa ser explorado. A própria escolha do tema proposto foi pensada através do diálogo com os alunos, trabalhando sobre os problemas que eles identificam.

\section{A Realidade da Periferia como Conteúdo: Uma Experiência em Maricá}

Nesse item encontra-se a apresentação da experiência vivida em Maricá, utilizando a metodologia dos temas geradores como uma prática de educação libertadora. Por uma educação conscientizadora, que não crie uma dicotomia entre a realidade experimentada em sua prática diária e o sujeito.

O município de Maricá localiza-se a uma distância de 60 quilômetros da cidade do Rio de Janeiro e possui uma população de aproximadamente 123.492 mil habitantes (IBGE, 2009). A experiência de prática de ensino foi realizada com uma turma do segundo ano do Ensino Médio composta por 20 alunos matriculados na escola Estadual Euclydes Paulo da Silva, localizada no bairro de São José de Imbassaí, na cidade de Maricá, região metropolitana do Rio de Janeiro. 
Desde o início do trabalho como professor nesta escola, observou-se a precariedade de infra-estrutura e serviços públicos daquela localidade. Além de assaltos e da insuficiência do transporte público naquele bairro, notou-se que os alunos sempre comentavam sobre os problemas enfrentados por quem residia ali e frequentemente depreciavam o lugar onde viviam. Somado a tudo isso, a falta de interesse dos alunos pelos conteúdos ensinados em sala de aula. A classe não se identificava com os assuntos do currículo de Geografia e por conta disso não enxergava a importância daquele conhecimento.

Diante disso, propôs-se ouvi-los sobre o que pensavam acerca da Geografia enquanto disciplina escolar. Em sala de aula foram apresentadas as seguintes perguntas:

1) Quantos aqui gostam de Geografia?

2) Aqueles que responderam gostar da disciplina apontem o porquê.

3) Aqueles que responderam não gostar de Geografia também devem apontar o porquê.

4) $O$ que vocês aprendem em Geografia?

5) Para que serve a Geografia escolar?

As respostas foram as seguintes:

1) Dos vinte alunos, doze deles responderam gostar de Geografia. Os demais não souberam responder. Nenhum aluno respondeu que não gosta ou detesta a disciplina.

2) Aqueles que responderam gostar de geografia justificaram sua resposta argumentando que "acham interessante aprender sobre os lugares, sobre outros países e etc"; e para ter cultura.

3) Aqueles que não afirmaram gostar de Geografia, disseram que a consideram uma "matéria chata, com muitas informações para serem absorvidas". Outros responderam:

- Para quê eu preciso saber sobre o clima ou a economia da Europa? Isso não me seve para nada.

4) Grande parte dos alunos respondeu que aprendem nas aulas de Geografia sobre "como são os outros países e o Brasil, e que isto é 
bom para manter-se informado".

5) Perguntados sobre para que serve a Geografia escolar, a classe insistiu na mesma resposta que deram ao serem perguntados sobre o que se aprende nas aulas de Geografia. Ou seja, não conseguiram visualizar a importância deste conhecimento para as suas vidas.

A partir daí, foi proposta uma atividade que aproximasse a realidade dos alunos das aulas. Ou seja, construir um saber que instrumentalizasse estes alunos para a vida e desenvolvesse o senso crítico acerca do conhecimento escolar e do cotidiano. Como um dos conteúdos a serem trabalhados com esta classe seria Urbanização Brasileira, e como eles viviam em uma região da periferia urbana, incorporou-se as experiências dos alunos como base para a discussão da matéria. Foi utilizada a metodologia dos "temas geradores", já explicada no item anterior.

Primeiramente, foi solicitado aos alunos que escrevessem um texto sobre o local onde moravam, desenvolvendo os seguintes aspectos:

1) Como é o local onde vivem?

2) Gostam ou não de viver lá?

3) Quais são as vantagens e os piores problemas do lugar onde moram ou o que precisa ser melhorado?

Surpreendentemente, todos os alunos da classe produziram um texto e entregaram na aula seguinte, pois não é comum toda a classe realizar uma atividade sugerida pelo professor. Dos textos, foram destacados:

1) Todos os alunos responderam gostar do lugar onde vivem.

2) Dezesseis alunos classificaram o lugar como bonito, com a presença de lagoas, praias e montanhas com matas. Realmente trata-se de um município com todos esses atrativos e está localizado numa zona de transição entre o urbano e o rural.

3) Os alunos apontaram as belezas naturais e os laços de afetividade e solidariedade com a vizinhança e familiares como as principais vantagens de viver lá. Foram muito comuns respostas como: "é bom viver lá porque tenho muitos amigos, toda minha família está aqui, as pessoas daqui são boas e amigas". 
4) Como piores problemas do lugar onde vivem, os alunos elegeram:

a) Todos alunos indicaram a falta de saneamento básico. Não há água encanada e muitas vezes o esgoto é lançado a céu aberto ou diretamente jogado nas lagoas.

b) Dezesseis alunos também apontaram: transporte público insuficiente, precário e caro. $\mathrm{O}$ bairro conta com número de linhas de ônibus limitado, sem respeito aos horários e a um preço muito alto, uma vez que, uma única empresa de ônibus possui o monopólio de todas as linhas do município.

c) Dez alunos também identificaram a falta de oportunidades de emprego na região e a precariedade dos serviços de saúde e educação pública como algo que os preocupa. Segundo eles, faltam profissionais no único posto de saúde do bairro e as escolas não são de boa qualidade e também sofrem com falta de profissionais.

d) Alguns alunos também citaram a falta de pavimentação e a irregularidade da coleta de lixo e a deficiência da iluminação pública, como graves problemas enfrentados pelos moradores.

e) Também apontaram a carência de espaços de lazer como algo que precisa ser melhorado no bairro. Não há locais nem projetos para a prática de esportes e outras formas de entretenimento.

f) Muitos também citaram a violência como algo que preocupa a população local. Segundo os alunos não há policiamento, é perigoso sair a noite e os assaltos são muito freqüentes.

g) TODOS os alunos concluíram que os governantes "não ligam" para o bairro; nada é feito para melhorar a vida dos moradores, que são tratados com descaso pelo poder público.

A partir da leitura dos textos produzidos pelos alunos, a proposta foi a de relacionar os conteúdos dos problemas vividos com as aulas de geografia urbana. De modo geral, os livros didáticos de geografia, ao tratar do assunto Urbanização Brasileira, exploram muito superficialmente os conceitos de periferia, espaço urbano e favelização. Ou seja, estas questões são citadas apenas, e não é uma discussão acerca de como estas realidades são produzidas. Por este motivo, foi desenvolvido com a classe elementos que permitissem a compreensão acerca da produção do espaço urbano. Tomando como base as situações relatadas pela turma, foi proposto sua análise a partir do conceito de segregação espacial, entendida aqui, de acordo com Villaça (2001 p .142), como "um processo segundo o qual diferentes classes ou camadas sociais tendem a se concentrar cada vez mais em diferentes regiões gerais ou conjuntos de bairros da metrópole". Ainda de acordo com o referido autor e obra, podemos considerar que a nossa experiência 
se dá em um caso típico do "mais conhecido padrão de segregação da metrópole brasileira: o do centro $x$ periferia". A periferia é predominantemente habitada pela população de baixa renda, como uma imposição dos sujeitos hegemônicos da produção do espaço urbano.

Foi proposto, então, a segregação espacial como "tema gerador"; a partir do qual os debates e conclusões do grupo seriam desenvolvidos, e a partir disso, outras categorias seriam apresentadas aos alunos com vistas a discuti-las a partir das demandas apresentadas em seus textos.

A proposta foi debatida com a turma em dois encontros. A bibliografia utilizada conta com o livro didático de geografia adotado pela escola dois livros sobre a temática urbana e a segregação, respectivamente:

MOREIRA, João C. e SENE, Eustáquio de. Geografia. São Paulo:

Scipione, 2005.

CORRÊA, Roberto Lobato. O espaço urbano. São Paulo: Ed. Ática, 2004. VILLAÇA, Flávio. O espaço intra-urbano no Brasil. São Paulo: FAPESP, 2001.

Como estes dois últimos livros são voltados para um público de nível superior e não para alunos de Ensino Médio, optou-se pela realização da leitura de ambos e seleção dos conceitos elementares para serem apresentados a turma durante a discussão. Ou seja, foram trabalhadas com os alunos passagens dos livros que tivessem correspondência direta com o que eles relataram nas redações.

Para iniciar o debate foi exposto no quadro-negro três questões principais, que nenhum aluno conseguiu responder, mas com o decorrer da discussão todos desenvolveram o os conceitos. As perguntas são as seguintes:

1)O que é espaço urbano?

2)Quem produz o espaço urbano?

3)O que é segregação sócio-espacial e quem a produz?

4)Como o espaço pode atuar como um mecanismo de exclusão?

As respostas a estas perguntas, os alunos tinham dentro de si e na sua experiência, mas não conseguiam elaborá-las em frases. Organizada a turma em círculo, foram devolvidas as redações que haviam escrito e reapresentadas as perguntas. Desde o primeiro momento, a turma se mostrou bastante interessada em debater, mas acharam as perguntas expostas no quadro muito complexas. Para 
enriquecer o debate e para introduzir os conceitos retirados dos livros, foi organizado um quadro-esquema que expusesse as ideias necessárias a compreensão da segregação espacial e de sua relação com a realidade dos alunos. Na verdade, este quadro apresentava os conceitos fundamentais extraídos das leituras indicadas. Como as perguntas norteadoras do debate foram colocadas no quadronegro, este esquema sugeria as respostas a estas perguntas.

Observe na figura 1 o esquema referente a questão de número 1.

Figura 1: A produção da cidade desigual

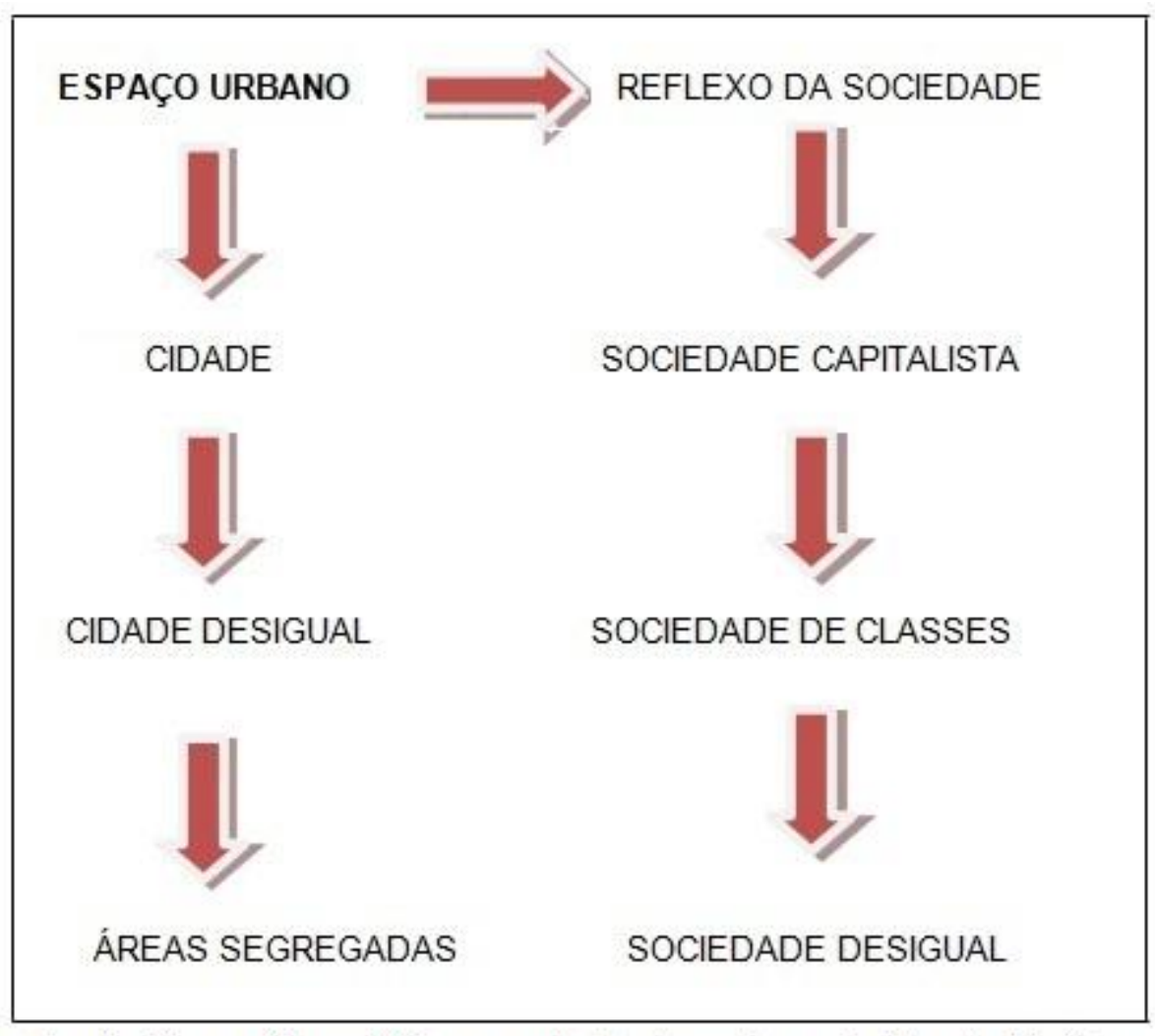

Produzido por Diego Marino a partir de elementos extraídos de Corrêa, 2004.

Através do quadro exposto na figura 1 , os elementos expostos têm como objetivo demonstrar que a produção da cidade no sistema capitalista expressa a realidade da luta de classe. As áreas segregadas produzidas são criadas em detrimento da formação de regiões privilegiadas pelos que tem acesso ao capital. É importante que os alunos consigam compreender essa relação da produção da cidade desigual.

Observe na figura 2 o esquema referente à questão de número 2

Figura 2: Os agentes produtores do espaço 


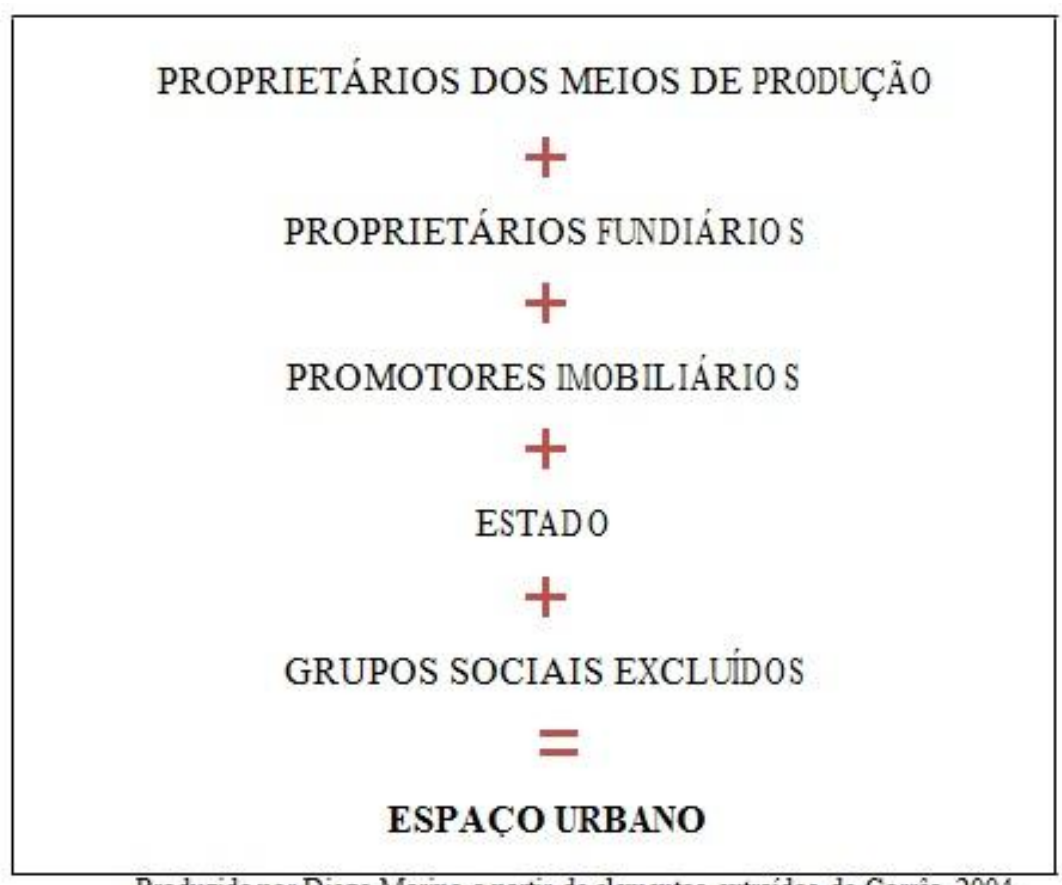

Produzido por Diego Marino a partir de elementos extraidos de Corrêa, 2004.

Os produtores do espaço urbano constituem um conjunto de forças que tem uma certa influência no processo de formação da cidade. Entre os responsáveis por essa formação estão os próprios alunos que caracterizaram os grupos sociais excluídos segundo a conclusão deles, mesmos ao falar do lugar onde vivem.

Observe na figura 3 o esquema referente à questão de número 3:

Figura 3: A produção da segregação

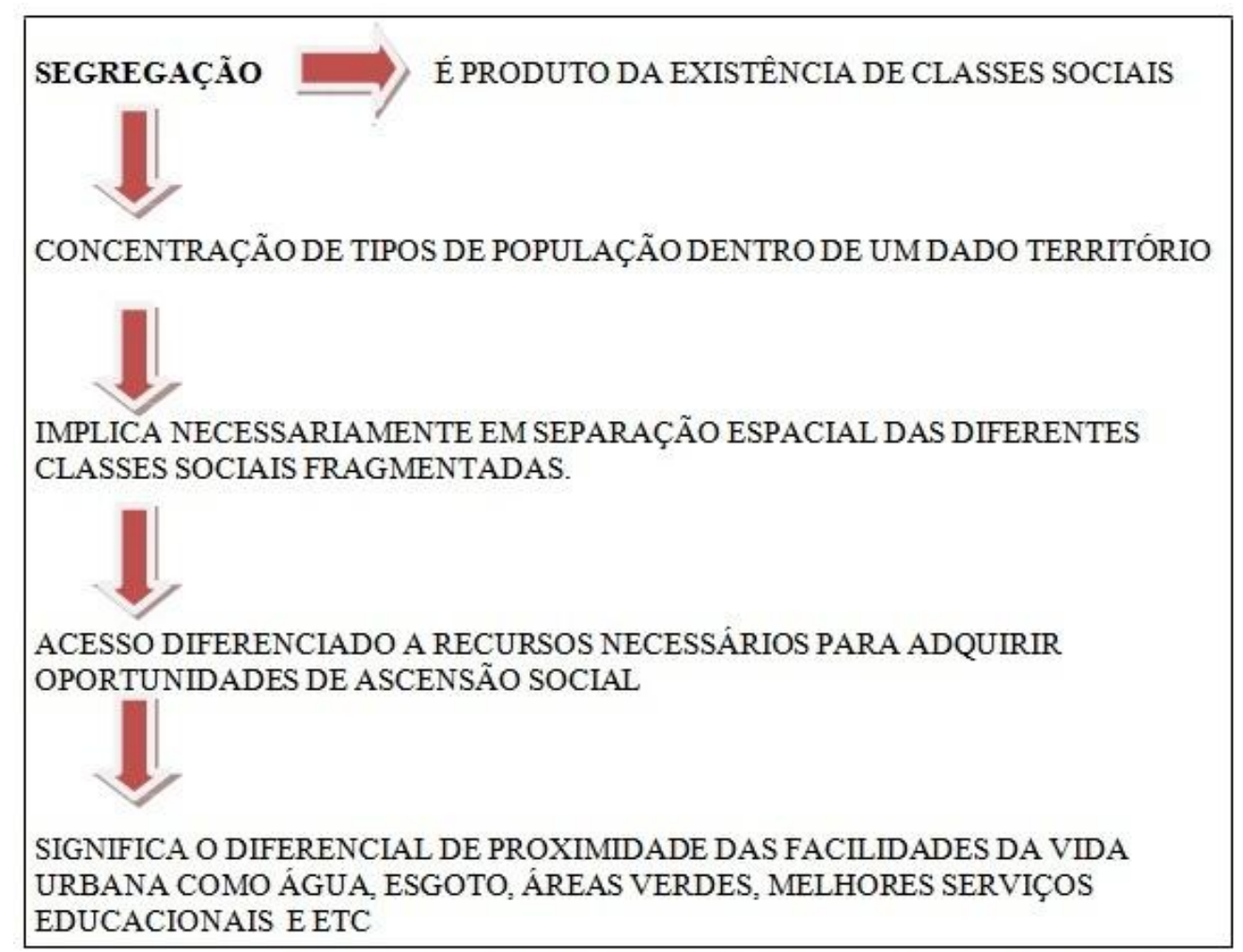

Produzido por Diego Marino a partir de elementos extraídos de Corrêa, 2004 e Villaça 2001. 
Segundo os próprios alunos, alguns problemas graves caracterizam o lugar onde vivem. Isso fica evidenciado quando, em sua redação, eles caracterizam esse bairro. No quadro acima se apresenta o conceito científico da segregação sócio-espacial, como a realidade vivenciada por eles e apresentando como essa é produzida.

Observe na figura 4 mais um esquema referente à questão de número 3:

Figura 4: As relações sociais de produção do espaço.

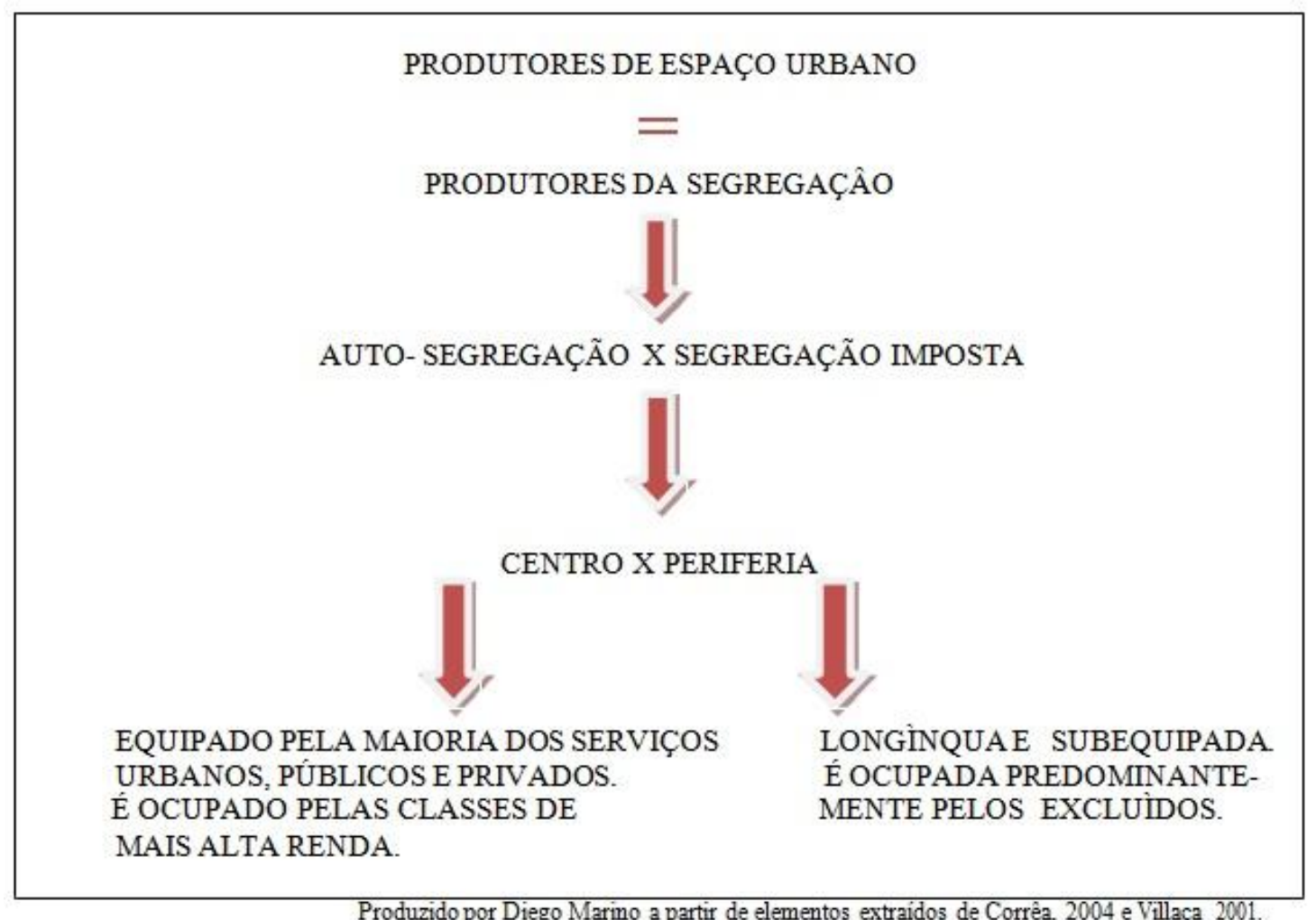

Apresentadas como o maior problema vivenciado pelos alunos, a ausência de serviços públicos reforça a ideia de que a desigualdade entre o centro e a periferia, vivenciada pelos mesmos, exemplifica a produção de um espaço diferenciado pelos que tem acesso ao capital e aqueles menos favorecidos. O Estado reforça essa relação ao distribuir de maneira desigual esses serviços.

O debate ocorreu da seguinte maneira: os alunos deveriam comentar seus textos, enquanto os pontos relevantes eram ressaltados e relacionados aos esquemas, exibidos em um projetor. Durante a discussão os alunos faziam suas associações e elaboravam respostas para as questões propostas. Apenas a quarta questão exposta no quadro não contava com um esquema, propositadamente. Foi proposto que a partir das discussões os alunos elaborassem, juntamente com o professor, um esquema que respondesse a última questão.

A conclusão da turma é mostrada no esquema da figura 5 : 
Figura 5: A produção da cidade segundo a conclusão da turma

OS PROPRIETÁRIOS FUNDIÁRIOS E OS PROMOTORES IMOBILIÁRIOS PROCURAM RETIRAR O MAIOR LUCRO POSSÍVEL DA VENDA DAS TERRAS E IMÓVEIS.

O ESTADO DISTRIBUI DE MANEIRA DESIGUAL OS INVESTIMENTOS EM INFRAESTRUTURA, ELE PRIVILEGIA AS AREAS ONDE RESIDEM AS CLASSES MAIS ALTAS.

AOS GRUPOS SOCIAIS EXCLUÍDOS É IMPOSTO MORAR EM LOTEAMENTOS PERIFÉRICOS OU FAVELAS.

A SEGREGAÇÃO SÓCIO-ESPACIAL FUNCIONA COMO UM OBSTÁCULO PARA QUE OS MAIS POBRES ALCANCEM MELHORES CONDIÇÕES DE VIDA

Produzido por Diego Marino e turma do segundo ano do Ensino Médio

A turma construiu em grupos as conclusões citadas no esquema acima. A produção de um espaço diferenciado, com áreas segregadas, demonstra exatamente a realidade vivenciada por esses grupos. Ao apresentar essas conclusões os alunos demonstram reconhecer a sua realidade, trabalhando com o conceito científico que lhe foi apresentado.

A produção do conhecimento promovida pelos alunos através de sua realidade reforça a ideia de uma educação transformadora, uma vez que os alunos conseguem vislumbrar a sua existência na realidade apresentada. $E$ a aproximação e aprendizagem do conceito científico através dos conceitos produzidos no cotidiano reforça a ideia se ensino-aprendizagem apresentada por Cavalcanti (2008).

\section{Considerações Finais}

Professores e alunos vivem momentos muito difíceis na educação pública do Brasil e no Estado do Rio de Janeiro isso não é diferente. A escola encontra-se cada vez mais incapaz de trazer novas perspectivas aos alunos, que estão cada vez mais desmotivados. Esse quadro faz com que o processo educativo seja apenas uma mera formalidade e reforce o quadro de segregação que os alunos estão submetidos. Entretanto, é necessário não esquecer os reais objetivos da 
educação e de como ela pode ajudar a transformar essa realidade opressora.

O movimento de renovação de geografia foi muito importante para o desenvolvimento de uma disciplina que apresenta a produção do espaço associada à luta de classe. Essa fase da ciência geográfica, entretanto não acabou com a realidade opressora que a escola apresenta. Os conteúdos são impostos aos alunos com a visão do professor, que não os enfatizam com o ponto de vista dos alunos.

O método de memorização da educação "bancária", que vê o aluno como um recipiente pronto para depositar informações, é um dos responsáveis pela falta de interesse; os conteúdos lecionados na escola de hoje não estão inspirados e nem inseridos na realidade do aluno, ou esses não visualizam essa proximidade. 0 educador que está envolvido em uma educação transformadora deve buscar um ensino que consiga fazer o aluno pensar a realidade em que vive e agir sobre ela.

Os temas geradores, retirados da pedagogia Freiriana e utilizados na pesquisa, permitiram aproveitar o universo sócio-espacial e cultural dos estudantes. Os alunos ficaram interessados no tema da aula, concentrados e participando dos debates a todo o momento. Outro ponto observado na experiência foi a capacidade dos alunos em propor soluções aos problemas expostos. Ao apresentar a segregação como um tema escolar, eles conseguiram compreender melhor o papel da escola, saindo da memorização e participando ativamente do processo.

Um fator importante observado nessa experiência foi o questionamento e as contribuições dos alunos em seus comentários relativos ao texto. Os alunos associavam aqueles textos a sua realidade e algumas ideias surgiram no decorrer da atividade. Alguns gostariam de ter mais espaço para falar, outros enfatizaram a necessidade da transformação através da ação dos mesmos. Sem dúvida alguma, a aula torna-se muito gratificante, na medida em que o aluno se torna ativo e questionador.

A partir do desenvolvimento desse trabalho é possível concluir que a metodologia Freiriana de trabalhar com temas geradores, visando retirar do universo temático do aluno temas inerentes a sua realidade fazendo dele um agente de sua própria educação, pode ser enriquecedora para uma prática libertadora de educação. A memorização de conteúdos, ainda muito marcante no ensino de geografia, apenas reforça a alienação desses alunos e a opressão das classes dominantes. Sua superação por um ensino problematizador torna gratificante tanto para os alunos como para os professores. 


\section{Notas}

1- Trabalho apresentado como requisito para obtenção do diploma de pós graduação em educação básica modalidade ensino de geografia

2- Aluno da Pós Graduação Educação Básica - Ensino de Geografia da Faculdade de Formação de Professores da UERJ; Professor da rede privada e do Estado do Rio de Janeiro

\section{Referências}

CASTELLAR, Sônia; VILHENA, Jerusa. Ensino de Geografia. São Paulo: Cengage Learning, 2009.

CAVALCANTI, Lana de Souza. Geografia, escola e construção de conhecimentos. Campinas: Papirus, 1998.

CAVALCANTI, Lana de Souza. A Geografia escolar e a cidade: Ensaios sobre o ensino de geografia para a vida urbana cotidiana. Campinas: Papirus, 2008.

CORRÊA, Roberto Lobato. O espaço urbano. São Paulo: Ática 2004.

FREIRE, Paulo. Educação como prática da liberdade. Rio de Janeiro: Paz e Terra, 1981.

Paulo. Pedagogia do Oprimido. Rio de Janeiro: Paz e Terra, 1987.

LACOSTE, Yves. A geografia - isso serve em primeiro lugar, para fazer a guerra. Campinas: Papirus, 2008.

MOREIRA, João Carlos e SENE, Eustáquio.Geografia .São Paulo: Scipione, 2005. MOREIRA, Ruy. Para onde vai o pensamento geográfico? Por uma epistemologia crítica.

São Paulo: Contexto, 2006.

SANTOS, Milton . Urbanização Brasileira. São Paulo: Edusp, 1995

STRAFORINI, Rafael. Ensinar geografia: o desafio da totalidade - mundo nas séries iniciais. São Paulo: Annablume, 2008.

VILLAÇA, Flávio. O espaço intra-urbano no Brasil. São Paulo: FAPESP,2001. 
REVISTA TAMOIOS

\section{Bibliografia}

FREIRE, Paulo. Pedagogia da Autonomia. Rio de Janeiro: Paz e Terra, 1983.

MOREIRA, Ruy. Pensar e ser geografia: ensaios de história, epistemologia e ontologia do espaço geográfico. São Paulo: Contexto, 2007.

SOUZA, Marcelo Lopes . O desafio metropolitano: um estudo sobre a problemática sócio -

espacial nas metrópoles brasileiras. Rio de Janeiro. Bertrand Brasil, 2005. 